University of Wollongong

Research Online

Faculty of Engineering and Information

Faculty of Engineering and Information

Sciences - Papers: Part A

Sciences

$1-1-2014$

Design and development of a novel displacement differential self-induced magnetorheological damper

\author{
Guoliang $\mathrm{Hu}$ \\ East China Jiaotong University, ghu@uow.edu.au \\ Yi Ru \\ East China Jiaotong University \\ Weihua Li \\ University of Wollongong, weihuali@uow.edu.au
}

Follow this and additional works at: https://ro.uow.edu.au/eispapers

Part of the Engineering Commons, and the Science and Technology Studies Commons

Research Online is the open access institutional repository for the University of Wollongong. For further information contact the UOW Library: research-pubs@uow.edu.au 


\title{
Design and development of a novel displacement differential self-induced magnetorheological damper
}

\begin{abstract}
This article presents the development of a novel magnetorheological damper which has a self-sensing ability. In this study, a linear variable differential sensor, which was based on the electromagnetic induction mechanism, was integrated with a conventional magnetorheological damper. The working principle, configuration, and prototype of the displacement differential self-induced magnetorheological damper based on the integrated linear variable differential sensor technology were presented. A mathematical model of the proposed displacement differential self-induced magnetorheological damper was established. The finite element model was built with two-dimensional Maxwell software and the magnetic simulations were presented. With this approach, the influence of the flux leakage, the winding cylinder in different basic values of structure parameters, and materials were determined to obtain an optimal displacement differential self-induced magnetorheological damper. Finally, the dynamic performance of the displacement differential self-induced magnetorheological damper was evaluated with a fatigue test machine. The experimental results indicated that the developed displacement differential self-induced magnetorheological damper based on the integrated linear variable differential sensor technology can output controllable damping force and displacement relative self-induced voltages simultaneously.
\end{abstract}

\section{Keywords}

self, induced, magnetorheological, damper, novel, design, displacement, development, differential

Disciplines

Engineering | Science and Technology Studies

\section{Publication Details}

Hu, G., Ru, Y. \& Li, W. (2014). Design and development of a novel displacement differential self-induced magnetorheological damper. Journal of Intelligent Material Systems and Structures, 26 (5), 527-540. 


\title{
Design and Development of a Novel Displacement Differential Self-induced
}

\section{Magnetorheological Damper}

\author{
Guoliang $\mathrm{Hu}^{1,2, *}$, Yi $\mathrm{Ru}^{1}$, and Weihua $\mathrm{Li}^{3, *}$ \\ ${ }^{1}$ School of Mechanical and Electronical Engineering, East China Jiaotong University, Nanchang, \\ Jiangxi Province 330013, P. R. China
}

${ }^{2}$ The State Key Laboratory of Fluid Power and Mechatronic Systems, Zhejiang University, Hangzhou, Zhejiang Province 310027, P. R. China

${ }^{3}$ School of Mechanical, Materials and Mechatronic Engineering, University of Wollongong, Wollongong, NSW 2522, Australia

*Author to whom any correspondence should be addressed.

E-mails: glhu@ecjtu.jx.cn,weihuali@uow.edu.au

\begin{abstract}
This paper presents the development of a novel magnetorheological damper (MRD) which has a self-sensing ability. In this study, a linear variable differential sensor (ILVDS), which was based on the electromagnetic induction mechanism, was integrated with a conventional MRD. The working principle, configuration and prototype of the displacement differential self-induced magnetorheological damper (D-DSMRD) based on the ILVDS technology was presented. A mathematical model of the proposed D-DSMRD was established. The finite element model was built with two-dimensional Maxwell software and the magnetic simulations were presented. With this approach, the influencing of the flux leakage, the winding cylinder in different basic values of structure parameters and materials were determined to obtain an optimal D-DSMRD. Finally, the dynamic performance of the D-DSMRD was evaluated with a fatigue test machine. The experimental results indicated that the developed D-DSMRD based on the ILVDS technology can output controllable damping force and displacement relative self-induced voltages simultaneously.
\end{abstract}

\section{Keywords}

displacement differential self-induced, magnetorheological damper (MRD), electromagnetic induction, finite element analysis, dynamic performance. 


\section{Introduction}

Magnetorheological fluid (MRF) is a smart material invented by Rabinow in the middle of the $20^{\text {th }}$ century (Rabinow, 1948). It can transform from a free-flowing state to a semi-solid state in milliseconds upon an external magnetic field is applied. This behavior is called a MR effect, which is a reversible and rapid effect. The MR effect depends mainly on the magnetic field intensity rather than outside temperature or impurities in fluids (Jolly et al., 1999; Bossis, et al. 2002). MRF has well been used to develop a variety of intelligent devices, such as MR dampers and MR clutches (Yao et al. 2002; Zhu et al. 2012; Yoo and Wereley, 2004; Li et al., 2009), which have been used in civil structure, bridge structure, vehicle suspension, automobile clutch, and so on (Lee and Choi, 2000; Gordaninejad et al. 2002; Li et al. 2007, Yu et al. 2009).

A schematic diagram of a MR damper (MRD) semi-active control system on mechanical structures is shown in Figure 1, which consists of several key components, such as MRD, sensors, mechanical structure, vibration force and control strategies. To effectively reduce the influence of vibration force on mechanical structures, the MRD semi-active control system chooses a closed-loop control to mechanical structures through the changing of controllable damping force under a direct current generated by the controller system according to the signal of force sensor and the response of displacement sensor. In order to simplify the structure of the MRD semi-active control system, reduce cost of daily maintain, improve the reliable of operation, and decrease the installation spaces, an innovative approach integrated a self-induced structure into MRD has been developed by a number of groups. The MRD which integrated self-induced structure could take place the traditional MRD with displacement sensor in semi-active control system on mechanical structures.

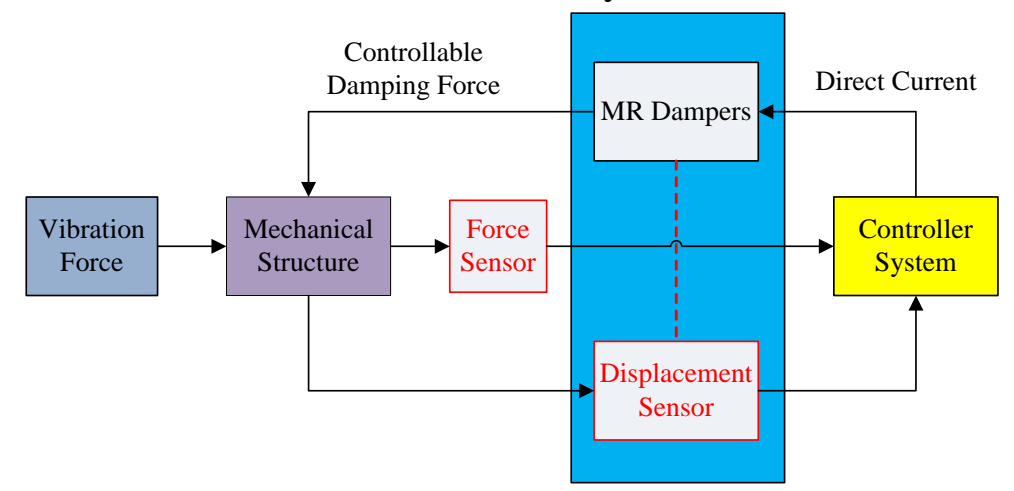

Figure 1. Schematic diagram of MRD semi-active control system structures

Chen et al. (2012) invented a self-powered and self-sensing MR damper which integrated a power part and sensor part. However, the complex structure and difficult installation make it hard to find practical applications. Wang and his co-workers proposed a novel modeling of integrated displacement self-sensing MR damper (Wang and Wang, 2009; Wang et al., 2010; Wang and Bai, 2011). Although the modeling was able to generate self-sensing voltages, the magnetic circuit is unstable by passing through the upper lid, and the reluctance of whole circuit is variable that makes the self-sensing voltages having theoretical deviation with true value. Additionally, the integration could degrade the performance of both sensing and damping capabilities. In their study, the Pareto optimization method was used to handle the tradeoff between the damping force and sensing performance. Wang et al. (2009) presented a new self-powered and sensing semi-active control 
system based on MR damper. The numerical simulation results showed that the two self-powered control strategy could get close performance with its corresponding semi-active control with external power supply. Lam et al. (2010) developed an MR damper with dual-sensing capability by integrating a piezoelectric force sensor and a displacement transducer with a conventional actuation-only MR damper. The experimental results showed that the MR damper with embedded force and displacement sensors had advantages in fulfilling real-time closed-loop feedback control applications for mitigating structural vibrations in a reliable and simple manner. Choi and Wereley (2009) studied the feasibility and effectiveness of a self-powered MR damper using a spring-mass electromagnetic induction device. Sapiński proposed a semi-active vibration control system comprising the EMI prototype and the damper RD 1005-3, and employed an electromagnetic transduction mechanism to extract energy from vibrations. The experiments demonstrated that the proposed system was able to power-supply the MR damper and the EMI acted as a 'velocity-sign' sensor (Sapinski, 2011). Nehl et al. (1996) developed an integrated relative velocity sensor which integrates into a liquid damper. The integrated relative velocity is working under the static magnetic field and output self-induced voltages dependent on velocity. The integrated plan above cannot be used into MR damper, because the self-induced static magnetic field would effect on the performance of damper seriously. We also proposed a self-sensing MR damper, whose performance was evaluated with simulation analysis (Peng et al., 2011). However, the accuracy of the self-sensing ability needs to be improved.

In this study, we extended our work in developing and prototyping a displacement differential self-induced MR damper (D-DSMRD) by integrating a linear variable differential sensor into a MRD for realizing a new functional MR damper that has the self-induced ability. This paper is organized as follows. Firstly, the working principle of the D-DSMRD was presented. The finite element model was then built with two-dimensional Maxwell software, and the magnetic simulations were also discussed. Finally, the dynamic performance of the developed D-DSMRD was experimentally evaluated.

\section{Principle and configuration of the D-DSMRD}

\subsection{Structure of the D-DSMRD}

In this study, a mixed mode combining both a flow mode and a direct-shear mode is chosen to design the proposed D-DSMRD. In this design as shown in Figure 2, an inner cylinder space is divided into two pressure chambers by a piston, where the MRF flows through the gap between the magnetize regions and outer cover from the high pressure chamber to the low pressure chamber. A magnetic circuit, formed by the excitation coil wound on the piston, is used to generate controllable magnetic field by varying the coil current. As shown in this figure, the MRF in the magnetic field of primary flux was magnetized based on the MR effect, which would output shear damping forces and valve damping forces. The resultant damping forces vary dynamically with the magnetic field generated by the excitation coil which input the direct current. 


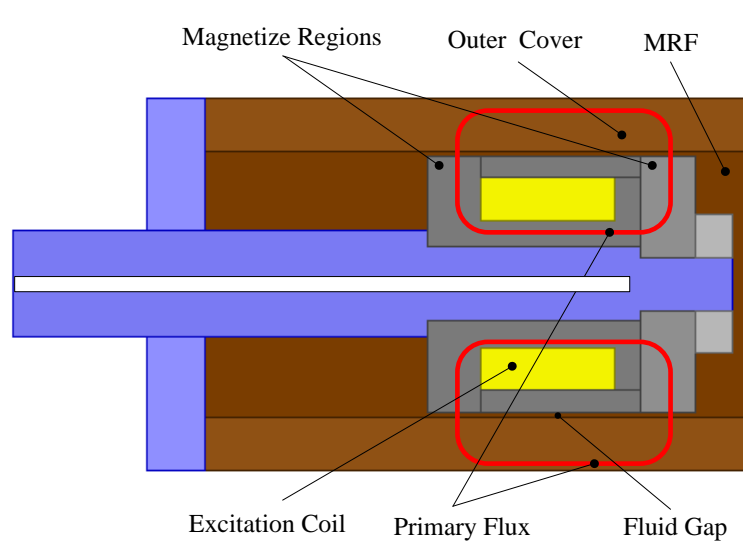

Figure 2. Principle diagram of flow mode and direct shear mode of MRD

The detailed structure of the proposed D-DSMRD is shown in Figure 3(a). It consists of a piston head which wound excitation coils, a winding cylinder which wound differential coils and an outer cover. Specifically, the coil wound on a piston head acting as an excitation coil, and providing magnetic fields to both ILVDS and MR fluids simultaneously, while differential coils wound on the winding cylinder to generate electromotive forces and output self-induced voltages. The piston head can input alternating currents in different frequencies and direct currents at the same time. The magnetic field generated by the alternating current enables differential coils to produce self-induced voltages, while the magnetic field generated by the direct current magnetizes the MRF in the annular channel. The input voltage is through hollow on the piston rod, and the output self-induced voltage is through the hollow on the outer cover.

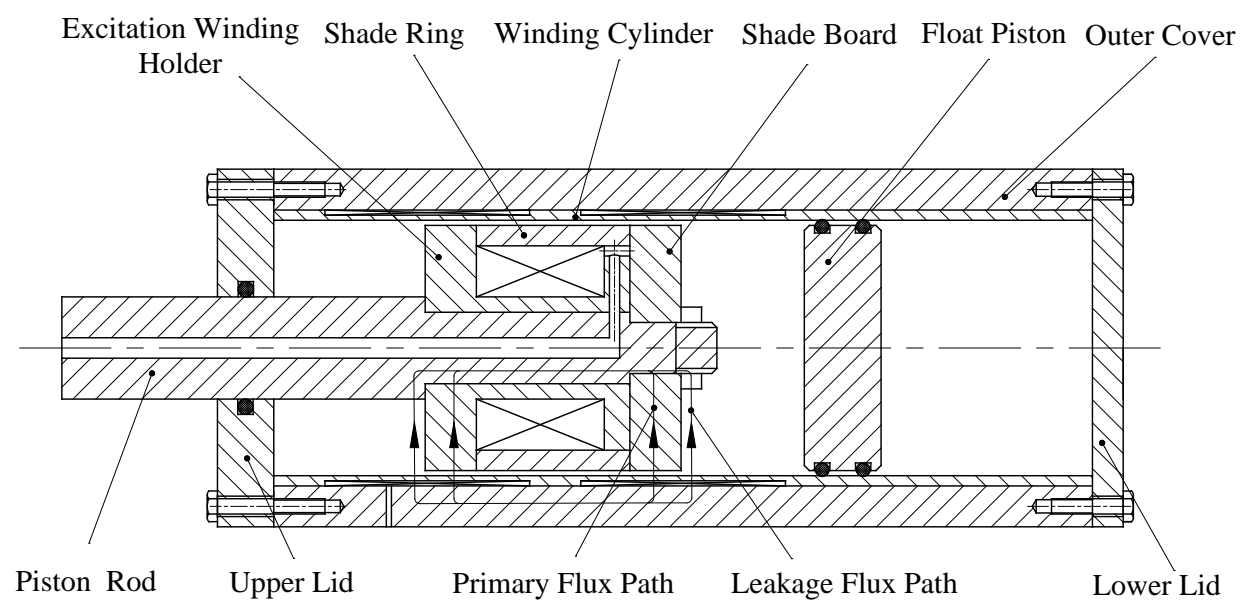

(a)

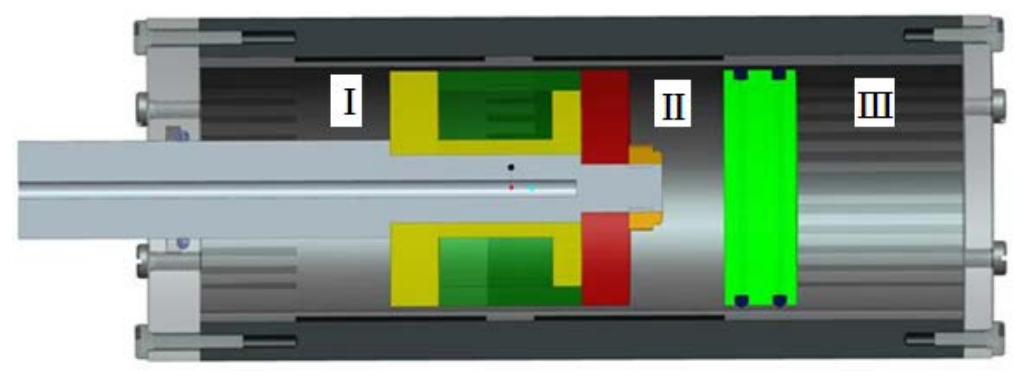

(b)

Figure 3. Structure of D-DSMRD: (a) CAD structure (b) Pro/E structure 
Similar to the traditional mixed mode that shown in Figure 2, the working magnetic circuit of the proposed D-DSMRD is shown in Figure 3(a), which has a leakage flux path, denoted by black lines with arrow, appeared nearby the primary magnetic path. A non-magnetic metal (stainless steel) was used to fabricate the piston rod, the winding cylinder, shade ring, the upper lid and the lower lid to avoid the magnetic circuit passing through, while a magnetic metal (10\# steel) was used to fabricate the piston, the shade board and the outer cover to generate a closed-loop working magnetic circuit. The output MRD damping force generally consists of two parts: the shear damping force and the valve damping forces, which are generated by shearing MR fluids in the gap by the difference pressures of two chambers, respectively.

\subsection{Controllable damping force of the D-DSMRD}

Based on the Bingham constitutive relation, the output damping force $F_{s v}$ is represented as

$$
F_{s v}=F_{s}+F_{v}
$$

where $F_{s}$ is the direct-shear damping force, given by

$$
F_{s}=\frac{\pi \eta D l}{h} v+\pi D l \tau_{y} \operatorname{sgn}(v)
$$

And the valve damping force $F_{v}$ is represented as

$$
F_{v}=\left[\frac{12 \eta l q}{\pi D h^{3}} v+\frac{3 l \tau_{y}}{h} \operatorname{sgn}(v)\right] s
$$

where $\eta$ is the viscosity of MR fluids, $l$ is the length of effective magnetic fields, $s$ is the effective regional area, $q$ is the volume flow of MRF, $D$ is the diameter of piston head, $d$ is the diameter of piston rod, $h$ is the thickness of fluid gap, $v$ is the velocity of piston, and $\tau_{\mathrm{y}}$ is the shear yield strength of MR fluids.

As shown in Figure 3(b), the whole chamber is composed of the upper lid, the winding cylinder and the lower lid. The whole structure of the D-DSMRD was divided into three parts, that is, I, II and III, by the piston and the float piston. The MRF in the parts I and II flows from high one to another, and air in part III is extruded or compressed. The pressures in these three parts depend on whether the fluid is in tensile or compression stage.

In the tensile stage, the pressure of part I is higher than others, and MRF in the MRD flows out from part I to part II; the volume flow at the tensile stage is given by

$$
q_{1}=v \pi\left(D^{2}-d^{2}\right) / 4
$$

In the compression stage, part II and part III are compressed by the piston, while part I is extruded; MRF flows in the MRD is out from part II to part I, the volume flow at the compression stage is

$$
q_{2}=v \pi\left(D^{2}-d^{2}\right) / 4
$$

Because the volume flow of tensile stage is equal to the volume flow of tensile stage, the effective area of part I is given by

$$
s=\pi\left(D^{2}-d^{2}\right) / 4
$$


So, the valve damping force of the D-DSMR damper is given by

$$
F_{v}=\frac{3 \pi \eta l\left(D^{2}-d^{2}\right)^{2}}{4 D h^{3}} v+\frac{3 \pi l \tau_{y}}{4 h}\left(D^{2}-d^{2}\right) \operatorname{sgn}(v)
$$

From equation (3) and (7), the whole output damping force is given by

$$
F_{s v}=\left[\frac{\pi \eta D l}{h}+\frac{3 \pi \eta l\left(D^{2}-d^{2}\right)^{2}}{4 D h^{3}}\right] v+\left[\pi D l+\frac{3 \pi l}{4 h}\left(D^{2}-d^{2}\right)\right] \tau_{y} \operatorname{sgn}(v)
$$

\subsection{Principle of differential self-induced technology for the D-DSMRD}

The key technology for differential self-induced ability in the D-DSMRD is an integrated linear variable differential sensor (ILVDS) method based on the electromagnetic induction. To save the installation space and maintain functions, the D-DSMRD structure reusing the excitation coil is wound on the piston as the exciting coil for the ILVDS, the self-induced coils are wound on the winding cylinder inner the outer cover, the alternating current is input to the excitation coil to generate alternating magnetic field for ILVDS. The structure of the ILVDS integrated in the D-DSMRD is shown in Figure 4, and the circuit diagram of ILVDS is shown in Figure 5. As shown in Figure 4, the D-DSMRD has the excitation coil wound on the piston (yellow color), the two differential self-induced coils for ILVDS wound on winding cylinder, the primary flux of self-induced magnetic path is shown in curve as red color, the leakage flux of self-induced magnetic path is shown in curve as green color. The magnetic circuit of ILVDS is the same as the magnetic circuit of MRD damping force. To build the D-DSMRD which integrated ILVDS, the self-induced magnetic circuit is ensured not to disturb the damping force magnetic circuit, and the leakage flux should be as small as possible.

The turn of the excitation coil in Figure 4 is denoted as $N$, the turn of excitation coils is denoted as $N_{1}$ and $N_{2}$ in Figure 5. $\dot{U}$ is the input excitation voltage, $\dot{U}_{1}$ is the output differential induced voltage, $L_{1}$ is the self-inductance of excitation coils, $L_{2}$ and $L_{3}$ are self-inductance of induced coils, $M_{1}$ is the mutual inductance between $N$ and $N_{1}, M_{2}$ is the mutual inductance between $N$ and $N_{2}, R_{1}$ is the resistance of excitation coils, $R_{2}$ and $R_{3}$ are the resistance of induced coils, respectively.

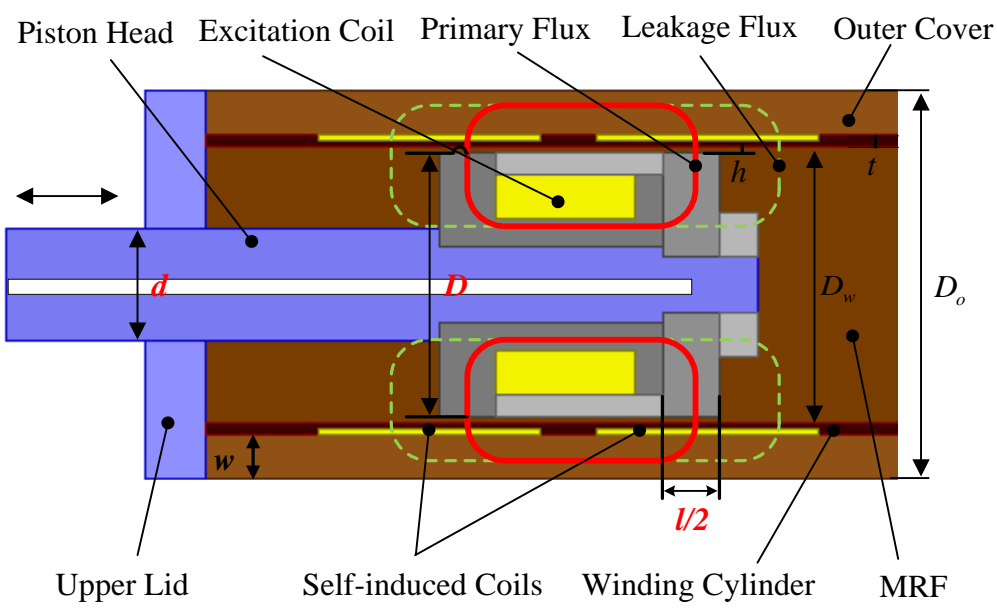

Figure 4. Principle diagram of D-DSMRD 


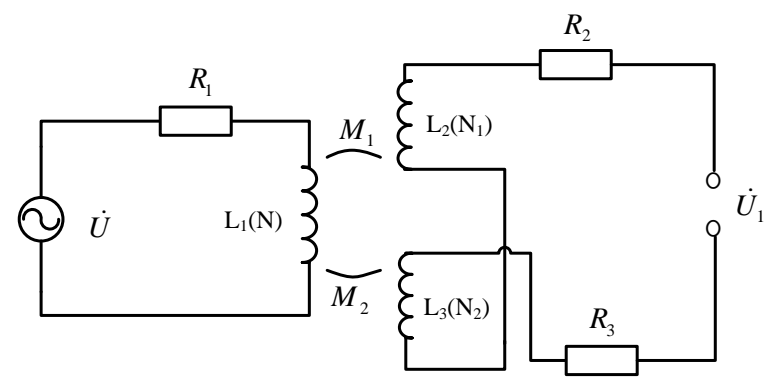

Figure 5. Circuit diagram of differential self-induced technology

The alternating current in excitation coils is given by

$$
\dot{I}=\frac{\dot{U}}{Z}=\frac{\dot{U}}{R_{1}+j \omega L_{1}}
$$

The electromotive forces of differential induced coils are given by

$$
\begin{aligned}
& E_{2}=-j \omega M_{1} \dot{I} \\
& E_{3}=-j \omega M_{2} \dot{I}
\end{aligned}
$$

The output differential induced voltage is

$$
\dot{U}_{1}=E_{2}-E_{3}=-j \omega\left(M_{1}-M_{2}\right) \frac{\dot{U}}{R_{1}+j \omega L_{1}}
$$

The mutual inductances of differential induced coils are

$$
\begin{aligned}
& M_{1}=\frac{N_{1} \phi}{I} \\
& M_{2}=\frac{N_{2} \phi}{I}
\end{aligned}
$$

The magnetic flux in induced coils is

$$
\phi=\frac{N I}{R}
$$

The reluctance of magnetic circuit is

$$
R=\sum \frac{l_{i}}{\mu_{i} S}+\frac{2 h}{\mu_{0} S_{0}}
$$

where $l_{i}$ is the length of the conductor in magnetic circuit, $\mu_{i}$ is the permeability of each section, $\mu_{0}$ is the permeability of vacuum, $h$ is the thickness of air gap, and $S_{0}$ is the area of the air cross-sectional. The self-inductance of excitation coils is defined as

$$
L_{1}=\frac{N^{2}}{R}
$$

Because of the $R_{1}<<\omega L_{1}$, the output induced voltage is derived as

$$
\dot{U}_{1} \approx \frac{M_{1}-M_{2}}{L_{1}} \dot{U}=\frac{2 \Delta N}{N} \dot{U}
$$


where $\Delta N$ is the change of $N_{1}$ and $N_{2}$, which is due to the movement of piston head, and it is given by

$$
\Delta N=\frac{\Delta S_{p}}{S_{c}}
$$

where $\Delta S_{\mathrm{p}}$ is the change of differential induced coils area $\mathrm{S}_{\mathrm{N}_{1}}$ and $\mathrm{S}_{N_{2}} \cdot \mathrm{S}_{\mathrm{C}}$ is the section surface of the induced coil.

$$
\Delta S_{p}=S_{N_{1}}-S_{N_{2}}=\Delta l \times h_{c}
$$

where $\Delta l$ is the relative displacement of piston head, $h_{\mathrm{c}}$ is the thickness of turns of the induced coils. Because the other parameters are constants, the output self-induced voltage $\dot{U}_{1}$ is linear with the relative displacement $\Delta l$. So the principle of the integrated ILVDS is ensured.

$$
\dot{U}_{1}=\frac{2 \Delta N}{N} \dot{U}=\frac{2 \Delta l \times h_{c}}{N \times S_{c}} \dot{U}
$$

\subsection{Model and simulation of the D-DSMRD with FEM}

In this section, a two-dimensional finite element model of D-DSMRD was built with the Maxwell 14.0 software as shown in Figure 6(a); the finite element model after meshing operation is shown in Figure 6(b). Because the finite element model is axisymmetric by the Y-axis, the performances of the D-DSMRD model in each sides of Y-axis are the same. As shown in Figure 6(a), this model had three material properties areas: (i) magnetic metal areas denoted as 1008 steel and copper provided by local database, such as excitation winding holder, shade ring, shade board and coils; (ii) nonmagnetic metal areas denoted as stainless steel searching in local database, such as upper lid, lower lid, piston rod, winding cylinder and float piston; and (iii) MRF material which is defined by nonlinear B-H curve. After assigning the materials areas of each parts of model, the 1.5A currents of excitation coils was set, the boundary of structures was provided, and the rules of simulation were also set. By finishing the preparation above, the simulation results were shown in Figure 7.

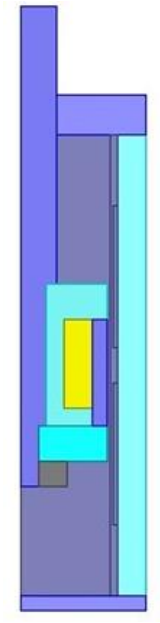

(a)

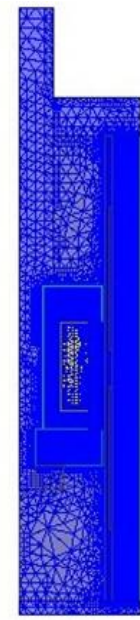

(b)

Figure 6. Two-dimensional finite element model of the D-DSMRD based on Maxwell 2D: (a) entity model, 
Figure 7(a) is the flux path of piston in D-DSMRD; Figure 7(b) is the magnetic induction intensity of D-DSMRD; and Figure 7(c) is the magnetic field intensity of D-DSMRD. From Figure 7(a), low level of flux leakage path appeared on the up side and down side of piston, high level of flux path appeared in the piston. As shown in Figure 7(b), the highest magnetic flux density, (from 1.85T to $2 \mathrm{~T}$, red color area) was in the inner piston; two sides of piston and inner out-cover have magnetic flux density ranging from $0.85 \mathrm{~T}$ to $1.4 \mathrm{~T}$ (green color area); and other parts (blue color areas) have the low flux densities (0 0.14T). From the magnetic simulation results in Figure 7(b) and 7(c), the high level magnetic induction intensity appeared in the MRF gap, which would well magnetize working MRF.

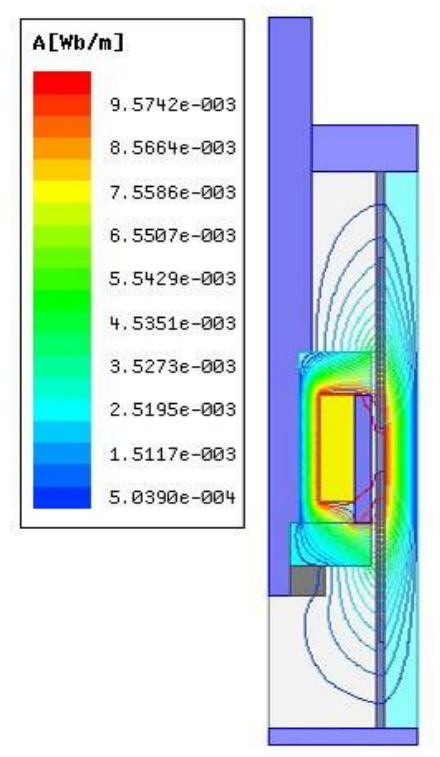

(a)

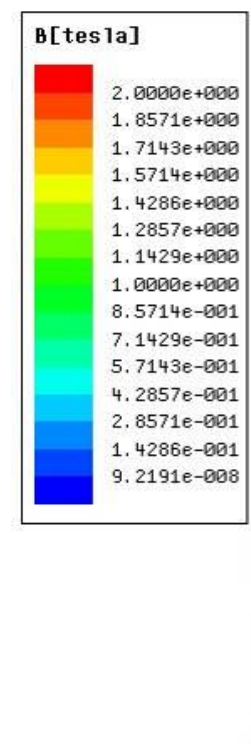

(b)

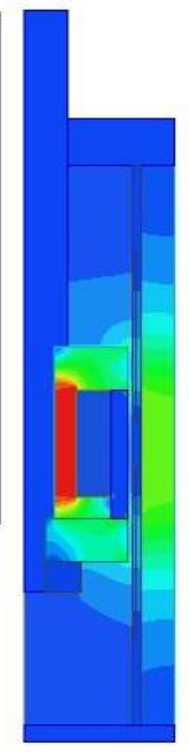

Figure 7. Magnetic simulation of the D-DSMRD: (a) flux path, (b) magnetic induction intensity, (c) magnetic field intensity

Magnetic flux leakage reduces the MRD performance, which should be taken into account for optimizing the damper performance. In this study, four finite element models were built, as shown in Figure 8 (a) to (d). The first model is a traditional MRD without self-induced function; the second model is the D-DSMRD with magnetic metal material (10\# steel) winding cylinder; the third model is the D-DSMRD with non-magnetic metal material (stainless steel) winding cylinder; and the fourth model is the D-DSMRD with other kinds of non-magnetic metal material (aluminum) winding cylinder. From the simulation results of four models above, the model of traditional MRD without winding cylinder has more concentrated flux path than the D-DSMRD model which has a winding cylinder. The model with a winding cylinder, which was made by a magnetic metal, such as $10 \#$ steel, has more concentrated flux path than the one made by non-magnetic metals. 


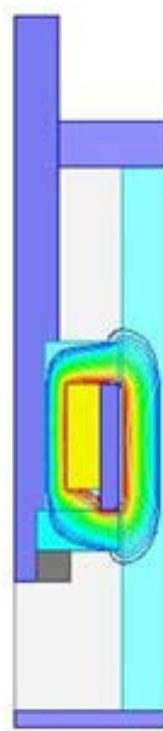

(a)

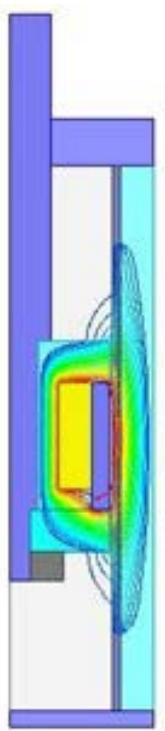

(b)

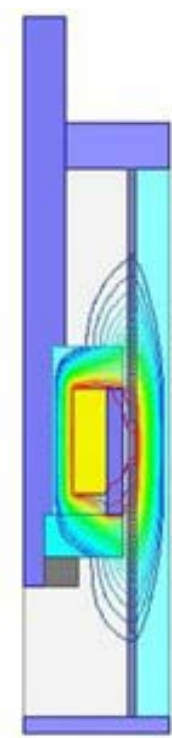

(c)

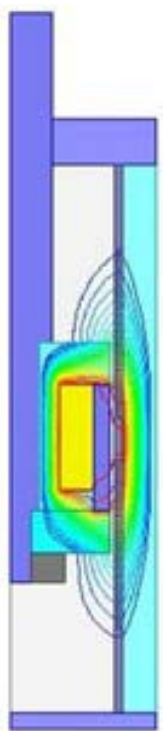

(d)

Figure 8. Leakage flux of different models: (a) none winding cylinder, (b) 10\# steel winding cylinder, (c) stainless steel winding cylinder, and (d) aluminum winding cylinder

The schematic of the winding cylinder in D-DSMRD is shown in Figure 9. The symbol $h$ is denoted as the thickness of winding cylinder, and the symbol $a$ is denoted as the winding depth. Two winding regions I and III are divided by the area II. In order to detect the relationship between the flux leakage and structures parameters and materials of winding cylinder, five D-DSMRD models of different structures and three D-DSMRD models of different materials were built. The selected parameters, which include three thicknesses and two winding depths, of the winding cylinder model were listed in table 1 . The flux reduction rates comparisons are shown in table 2, the self-induced voltages comparison are shown in table 3.

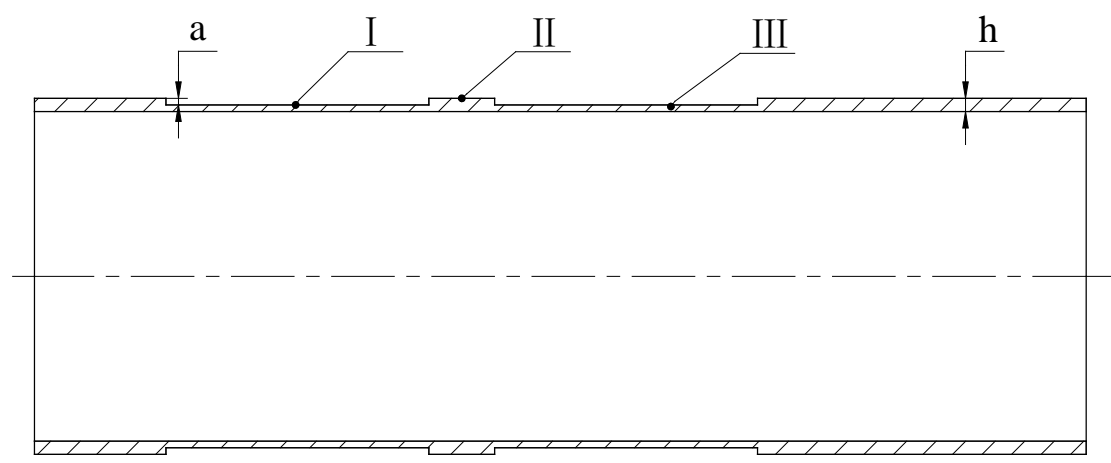

Figure 9. Schematic of the winding cylinder for the D-DSMRD

Table 1. Selected parameters of the winding cylinder

\begin{tabular}{ccc}
\hline Structure & Winding cylinder thickness & Winding depth \\
\hline I & $2 \mathrm{~mm}$ & $1 \mathrm{~mm}$ \\
II & $3 \mathrm{~mm}$ & $1 \mathrm{~mm}$ \\
III & $3 \mathrm{~mm}$ & $2 \mathrm{~mm}$ \\
IV & $4 \mathrm{~mm}$ & $1 \mathrm{~mm}$ \\
V & $4 \mathrm{~mm}$ & $2 \mathrm{~mm}$ \\
\hline
\end{tabular}


As is shown in table 2, the flux reduction rates of $10 \#$ steel are much lower than others, while the flux reduction rates of stainless steel are almost the same as the aluminum ones, which means that the magnetic metal winding cylinder would produce more concentration flux and lower flux reduction rate than non-magnetic metal winding cylinders. By comparing the flux reduction rate in $10 \#$ steel structures, the reduction rate I was $1.302 \%$ and lower than the III but higher than others. The flux reduction rate II was $0.516 \%$, which was the lower than the other reduction rates among structure IV and V. By comparing the flux reduction rate in stainless steel structures, the reduction rate I was $9.636 \%$, which was the lowest of other three structures; and the flux reduction rate of structure II was close to the flux reduction rate of structure III.

Table 2. Relation between the winding cylinder and magnetic flux reduction rate in fluid gap

\begin{tabular}{c|ccc} 
& & & \\
Material & 10\# steel & stainless steel & aluminum \\
\hline I & & & \\
II & $1.302 \%$ & $9.636 \%$ & $9.626 \%$ \\
III & $0.516 \%$ & $12.061 \%$ & $12.061 \%$ \\
IV & $1.764 \%$ & $12.027 \%$ & $12.027 \%$ \\
V & $0.262 \%$ & $13.971 \%$ & $13.991 \%$ \\
\hline
\end{tabular}

Table 3. Relation between the structures, materials of winding cylinder and self-induced voltage

\begin{tabular}{c|ccc}
\hline Material & 10\# steel & stainless steel & aluminum \\
\hline I & & & \\
II & $0.092 \mathrm{v}$ & $0.090 \mathrm{v}$ & $0.090 \mathrm{v}$ \\
III & $0.078 \mathrm{v}$ & $0.083 \mathrm{v}$ & $0.083 \mathrm{v}$ \\
IV & $0.181 \mathrm{v}$ & $0.167 \mathrm{v}$ & $0.167 \mathrm{v}$ \\
V & $0.069 \mathrm{v}$ & $0.078 \mathrm{v}$ & $0.078 \mathrm{v}$ \\
\hline
\end{tabular}

As is shown in tables 2 and 3, in the 10\# steel model, more winding depth will produce more flux leakage and generate more self-induced voltages by holding more turns of self-induced coils; more winding cylinder thickness would reduce self-induced voltages. In stainless steel model, more winding depth will produce more flux leakage and generate more self-induced voltages; more winding cylinder thickness would decrease self-induced voltages. In the aluminum model, the simulation results are the same as the stainless steel model.

From the simulation results above, the thick winding cylinder has higher flux reduction rate than the thin winding cylinder. Thus, the way to optimize the magnetic circuit of D-DSMRD damper was choosing the thin thickness winding cylinder of non-magnetic material (stainless steel).

\subsection{Prototype of the D-DSMRD}

The dimensions of the developed D-DSMRD were listed in Table 4. The photographs of parts, partial assembled and prototype of the D-DSMRD are shown in Figures 10(a), 10(b), and 10(c), 
respectively.

Table 4. Basic values of the structure parameters for the D-DSMRD

\begin{tabular}{c} 
Parameter \\
Piston rod diameter \\
Piston head diameter \\
Effective length \\
Gap thickness \\
Winding cylinder inner diameter \\
Outer-cover outside diameter \\
Piston effective displacement \\
Winding cylinder thickness \\
Outer-cover thickness \\
Excitation coil turns \\
Self-induced coil turns \\
\hline Self-induced coil turns \\
\hline
\end{tabular}

(a)

Symbol
$d$
$D$
$l$
$h$
$D_{w}$
$D_{0}$
$l_{\mathrm{p}}$
$t$
$w$
$N$
$N_{1}$
$N_{2}$

(b)
Basic Values

$20 \mathrm{~mm}$

$48 \mathrm{~mm}$

$20 \mathrm{~mm}$

$1 \mathrm{~mm}$

$50 \mathrm{~mm}$

$70 \mathrm{~mm}$

$40 \mathrm{~mm}$

$2 \mathrm{~mm}$

$10 \mathrm{~mm}$

950

160

160

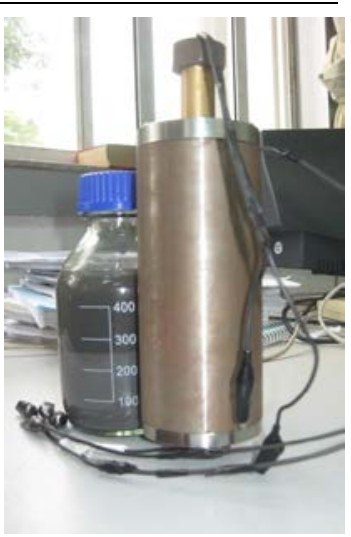

(c)

Figure 10. Assembly and prototype of the D-DSMRD: (a) parts of the D-DSMRD, (b) partial assembled of the D-DSMRD, and (c) prototype of the D-DSMRD

\section{Experimental evaluation of the D-DSMR damper}

\subsection{Sensor performance characteristics}

In order to acquire the self-induced voltages generated from movement of piston rod, both a signal acquiring module and an analysis module was built by LabVIEW software, which was shown in Figure 11(a) and 11(b), respectively. By using the signal acquiring module, the self-induced voltage amplitude and power spectrum can be shown on waveform graphs, where the amplitude of voltages can be adjusted by a knob. The signal data are written into the ".lvm" documents by entering the press of "save graph", and the waveform documents can be opened by the analysis module. Additionally, the waveform data can be analyzed, printed and saved as *.xls documents or *.jpg documents. 


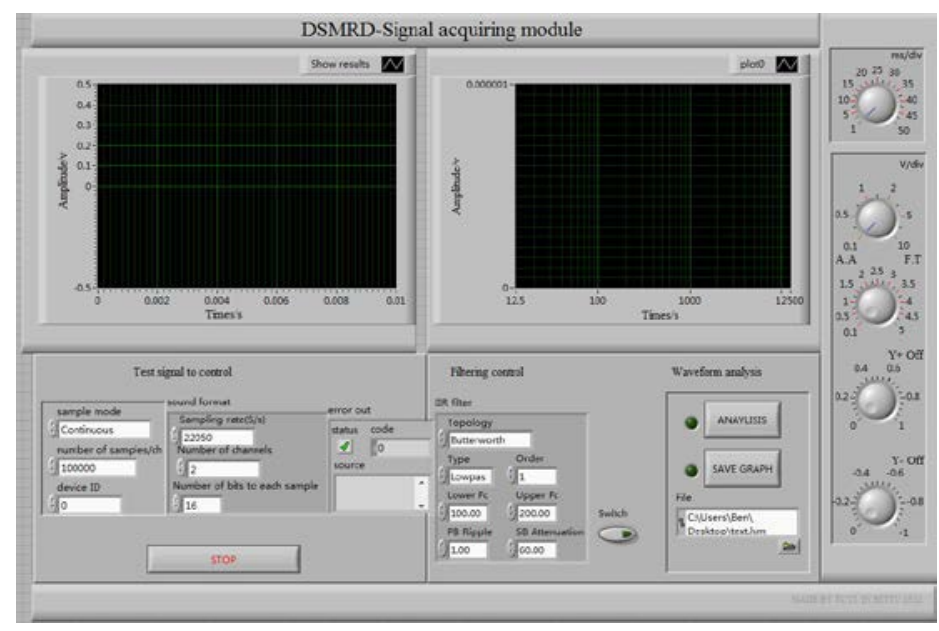

(a)

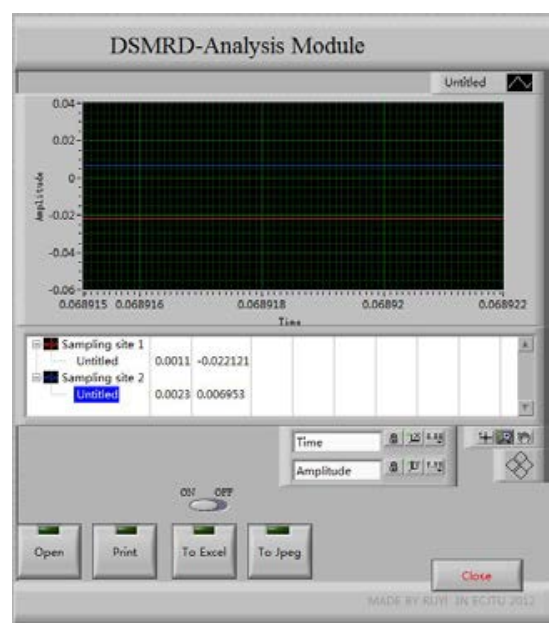

(b)

Figure 11. Front panel of signal acquiring and analysis module: (a) signal acquiring module, (b) analysis module.

The photograph of the experimental set up for testing the prototyped D-DSMR damper was shown in Figure 12. The alternating current excitation voltage was supported by SET-998+ experimental instrument, the differential coils were connecting to the data input port of audio card.

\subsubsection{Self-induced voltages under three positions}

With the frequency of $1 \mathrm{kHz}$ and amplitude of $0.84 \mathrm{~V}$ of sinusoidal excitation, a random position were chosen and denoted as position 1 , the distance from position 1 to 2 is $10 \mathrm{~mm}$, and the distance from position 2 to 3 is $10 \mathrm{~mm}$. The self-induced voltages of testing results in three positions were shown in Figure 13. Figure 13 (a)-(c) show the D-DSMRD self-induced voltage waveform during position 1 to 2, which indicate that the self-induced voltage has a clear increase when the piston rod moves. Figure 13(d)-(f) were the differential self-induced voltage waveform during position 2 to 3. The self-induced voltages had the same trends as the position 1 to 2 , and the waveform also had little distortions.

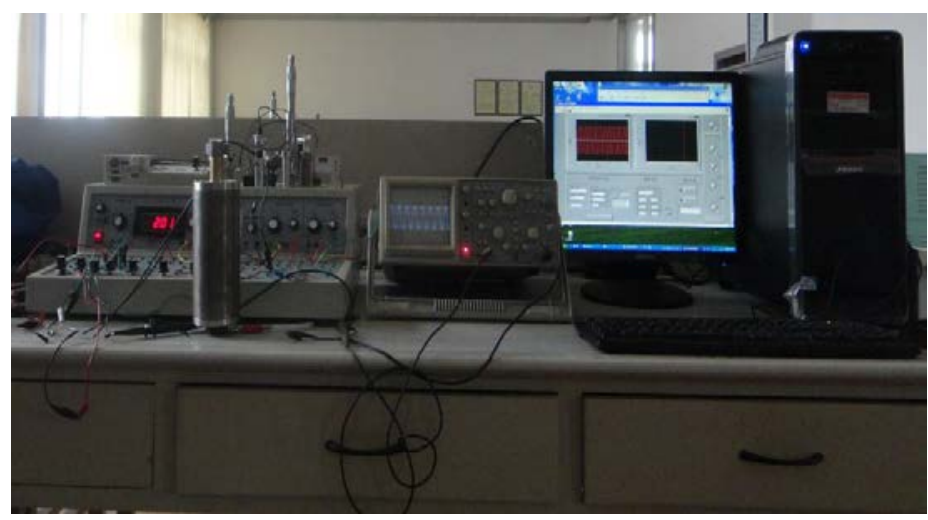

Figure 12. Self-induced testing plan of the D-DSMRD in static state 


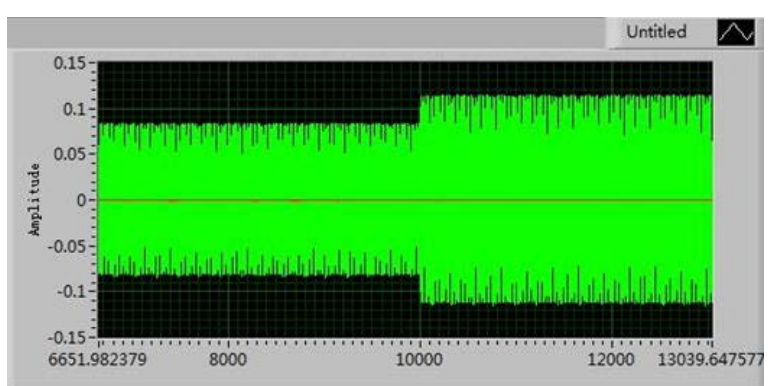

(a)

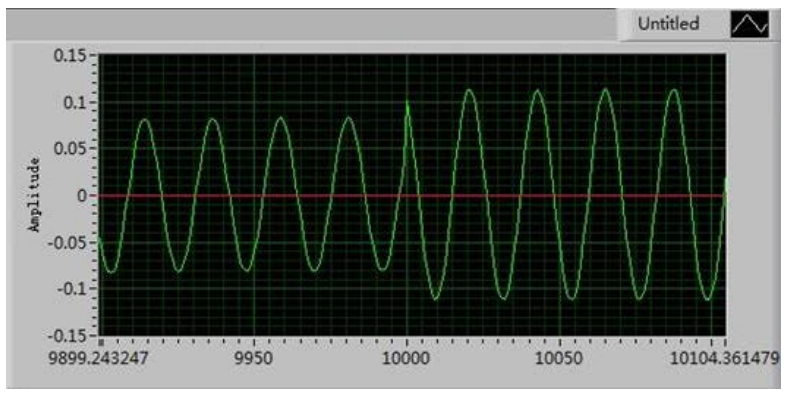

(c)

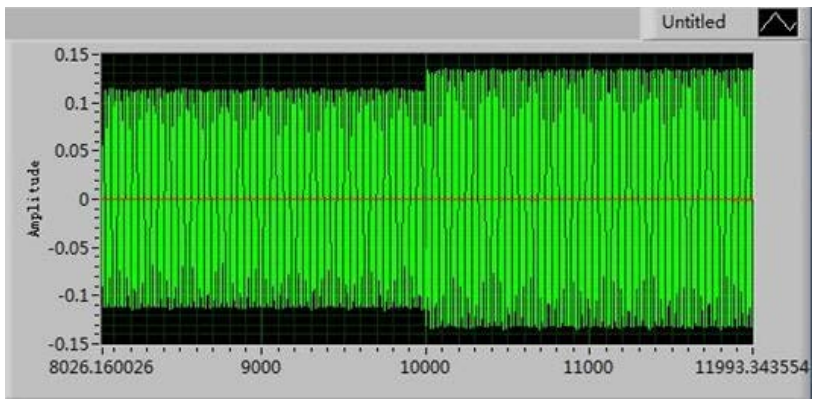

(e)

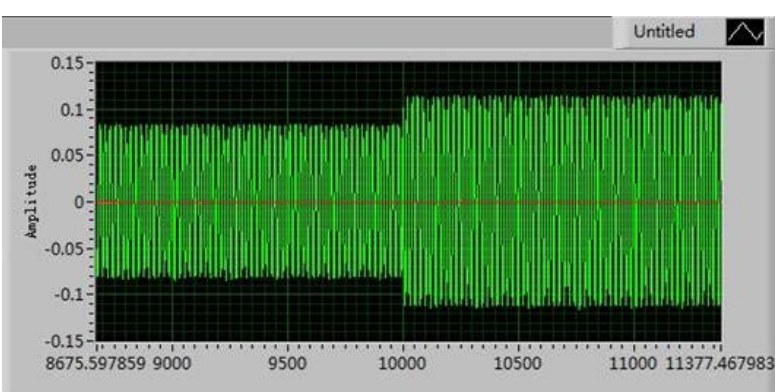

(b)

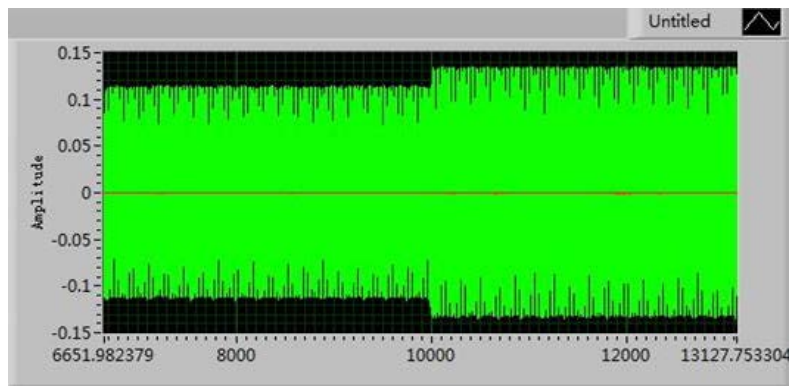

(d)

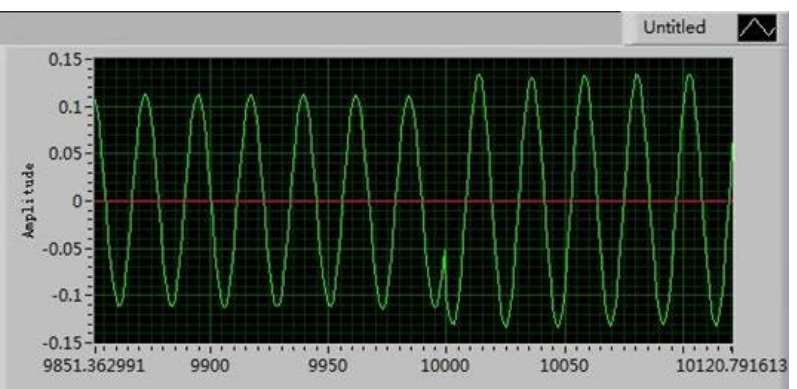

(f)

Figure 13. Self-induced voltages in three positions: (a) the waveform of self-induced voltage from position 1 to 2 , (b) the interception waveform of position 1 to 2 after enlarge $x$-axis, (c) the local waveform of 1 to 2 fully enlarged, (d) the waveform of self-induced voltage from position 2 to 3, (e) the interception waveform of 2 to 3 after enlarge x-axis, (f) the local waveform of 2 to 3 fully enlarged.

Figure 14 shows the self-induced voltages at three positions, where the black color was denoted as voltage in position 1; the red color was denoted as voltage in position 2; and the blue color was denoted as the voltage in position 3 . The peak values of the self-induced voltages at these three positions were summarized in Table 5. Though the distance of position 1 to 2 and the distance of position 2 to 3 were both set as $10 \mathrm{~mm}$, the self-induced voltage drop from position 1 to 2 is not the same as that from position 2 to 3 . The deviation might be due to the possible errors such as fabrication error and measurement error. Because of the fabrication error, the winding depth of two winding areas are not the same, the turns of each section in two areas are not exactly the same. Because of the measurement error, the real distances of each position are not exactly the same as well. To reduce the deviation, higher processing accuracy and measurement accuracy should be guaranteed in the next experiment. 


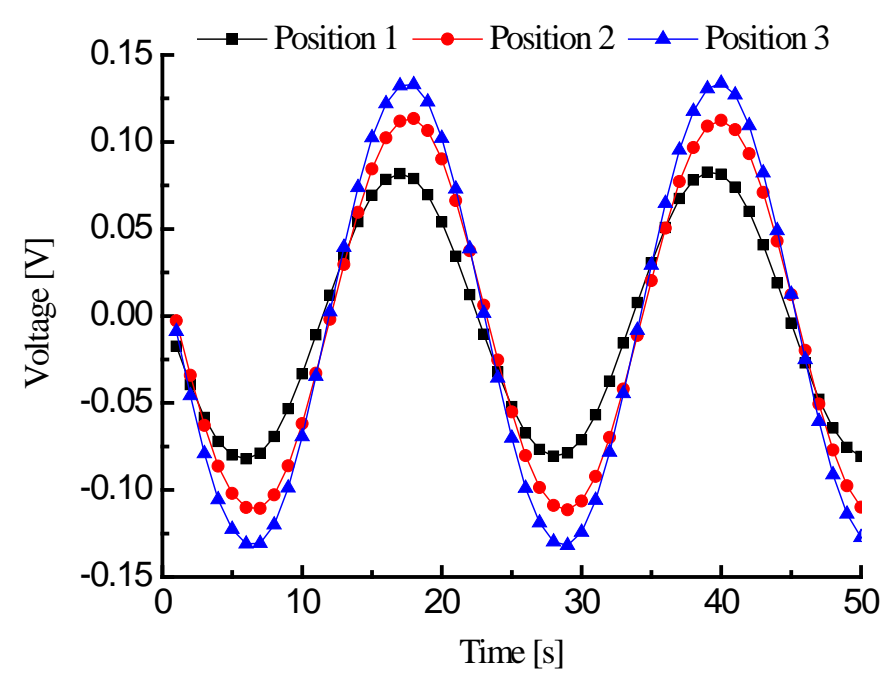

Figure 14. Comparison of D-DSMRD self-induced voltages

Table 5. Self-induced voltages in three positions

\begin{tabular}{cccc}
\hline Position & 1 & 2 & 3 \\
\hline Self-induced voltage(V) & 0.0816 & 0.1129 & 0.1338 \\
\hline
\end{tabular}

\subsubsection{Self-induced voltages under different DC inputs for the excitation coil}

Figure 15 shows the self-induced voltage under different DC inputs for the excitation coil. The testing frequency was $1 \mathrm{~Hz}$ and the damper displacement was set as from $-7.5 \mathrm{~mm}$ to $+7.5 \mathrm{~mm}$, which was provided by the fatigue test machine. The alternating voltage value is $6.0 \mathrm{~V}$ and the frequency is $1 \mathrm{kHz}$. From Fig.15, it can be seen that the maximum self-induced voltage basically remain unchanged though the DC inputs for the excitation coil increased from 0.25A to 0.75A. Specifically, the maximum self-induced voltages are $0.158 \mathrm{~V}, 0.156 \mathrm{~V}$ and $0.159 \mathrm{~V}$ when the DC inputs are $0.25 \mathrm{~A}$, $0.50 \mathrm{~A}$ and $0.75 \mathrm{~A}$, respectively. The deviation is within $2 \%$. Thus, it is concluded that the DC input has little influence of the output of the self-induced voltage.

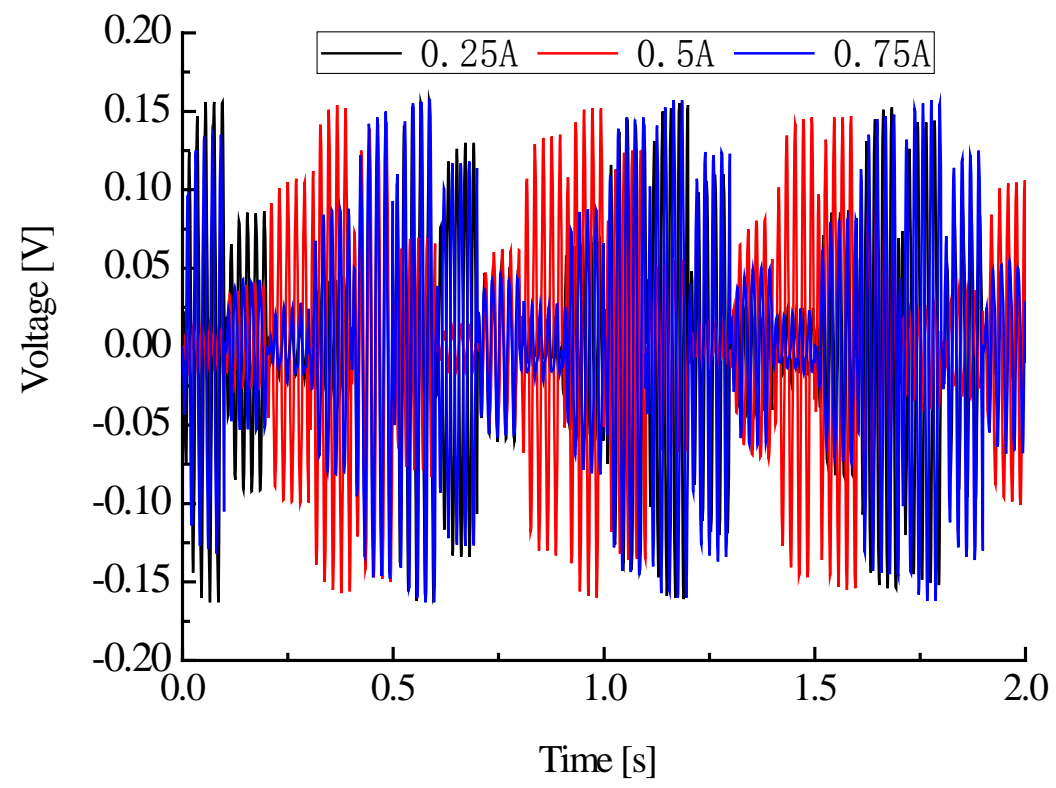

Figure 15. Self-induced voltage under different direct current inputs for the excitation coil as the damper 


\subsubsection{Self-induced voltages under different displacements}

Figure 16 shows the self-induced voltage under different damper displacement inputs. The testing frequency was $1 \mathrm{~Hz}$ and the damper displacement was set $2 \mathrm{~mm}, 3 \mathrm{~mm}, 4 \mathrm{~mm}, 5 \mathrm{~mm}$, and $6 \mathrm{~mm}$, respectively. The DC input for the excitation coil was set as $0.5 \mathrm{~A}$, the $\mathrm{AC}$ voltage is $6.0 \mathrm{~V}$ and the frequency is $1 \mathrm{kHz}$. As expected, the self-induced voltage is increased with the increase of the damper displacement.

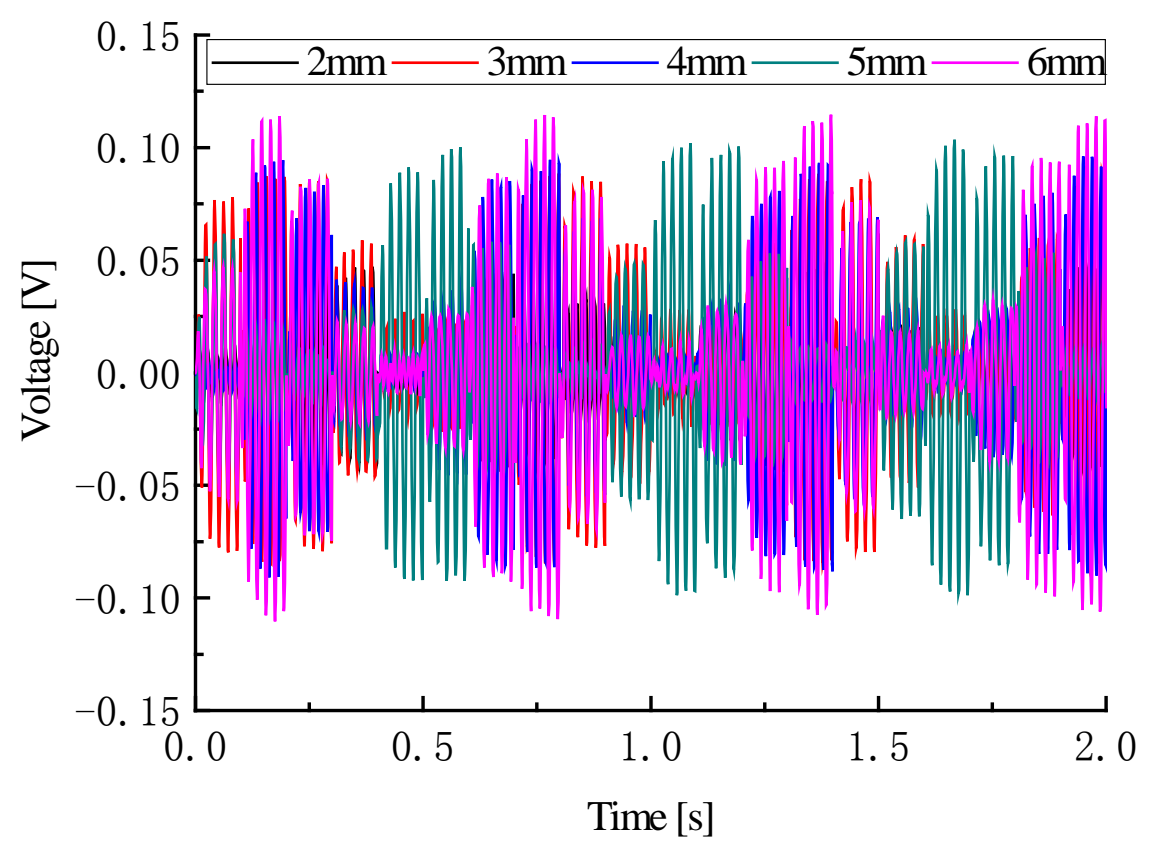

Figure 16. Self-induced voltage under different damper displacement excitation inputs as the direct current input was set $0.5 \mathrm{~A}$

Table 6 and Figure 17 show the self-induced voltage under different damper displacement. It can be seen that the self-induced voltage is proportional to the damper displacement, which demonstrates that the prototyped DSMRD has the ability of displacement integration. However, there is an offset when the displacement is zero. This is because the damper piston head deviates from the zero position in the process of clamping.

Table 6. Self-induced voltage under different damper displacement

\begin{tabular}{cccccc}
\hline Damper displacement [mm] & 2 & 3 & 4 & 5 & 6 \\
\hline Self-induced voltage [V] & 0.070 & 0.081 & 0.092 & 0.104 & 0.115 \\
\hline
\end{tabular}




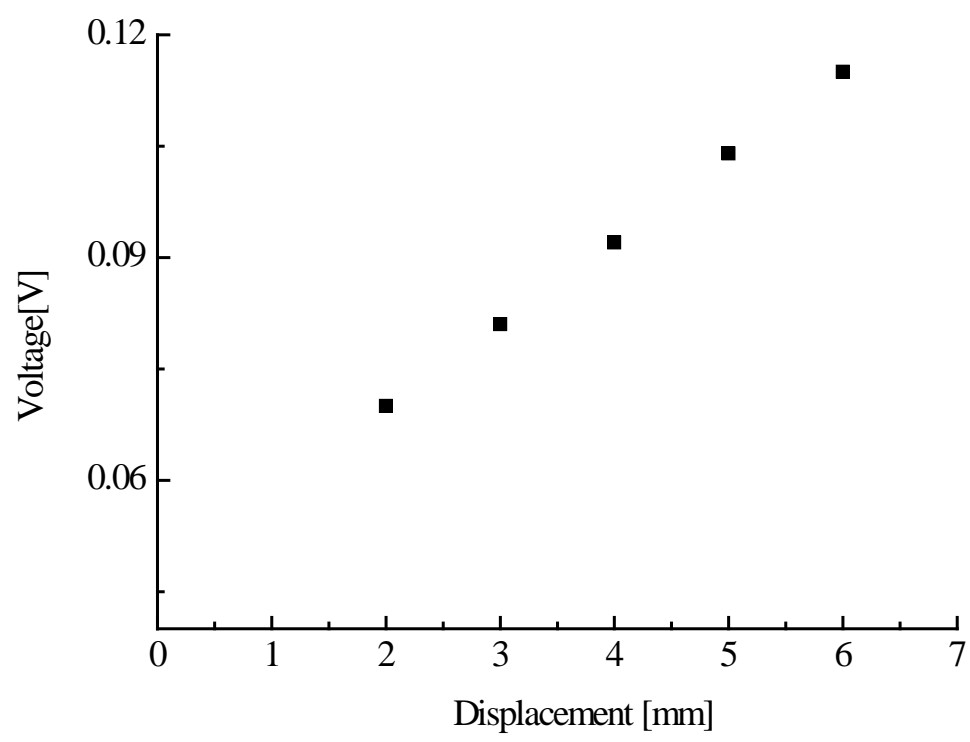

Figure 17. Self-induced voltage under different damper displacement

\subsubsection{Self-induced voltages under continuously varying DC inputs}

Figure 18 shows the self-induced voltages under continuously varying DC input for the excitation coil. The testing frequency was $1 \mathrm{~Hz}$ and the damper displacement was set from $-5 \mathrm{~mm}$ to $+5 \mathrm{~mm}$. The AC voltage is $6.0 \mathrm{~V}$ and the frequency is $1 \mathrm{kHz}$. From Fig. 18(a), it can be seen that the self-induced voltage maintains a certain value though the DC input for the excitation coil is changed from 0 A to $1 \mathrm{~A}$ continuously. A further examination of the circled part is enlarged and shown in Fig. 18 (b), where the maximum value of the self-induced voltage is $0.075 \mathrm{~V}$ during the movement of the DSMRD. Thus, the self-induced coils will not be disturbed by the excitation coil of the MR damper.

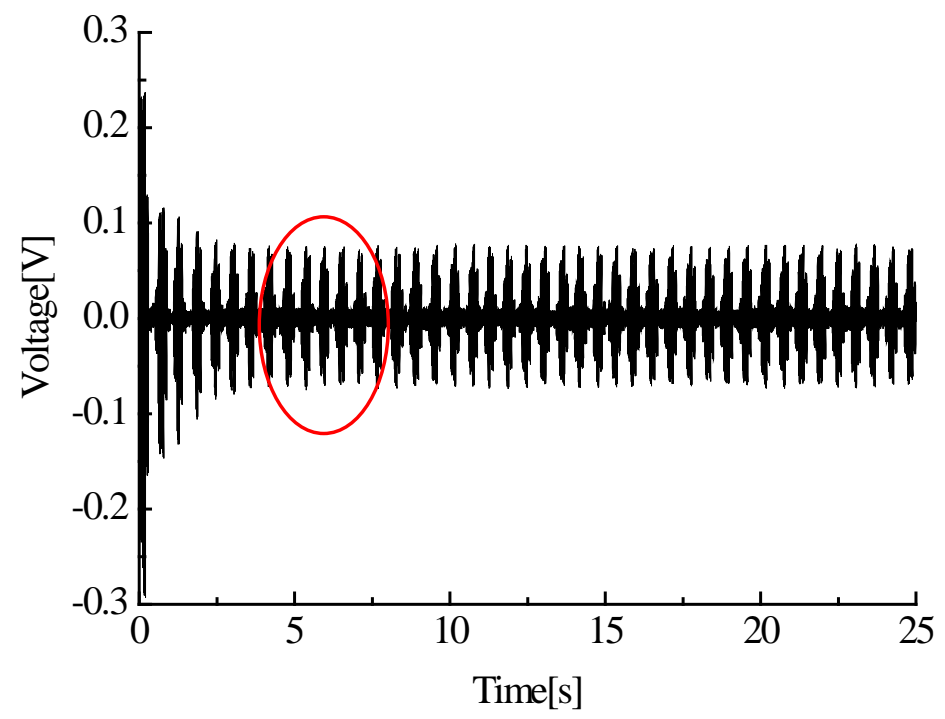

(a) 


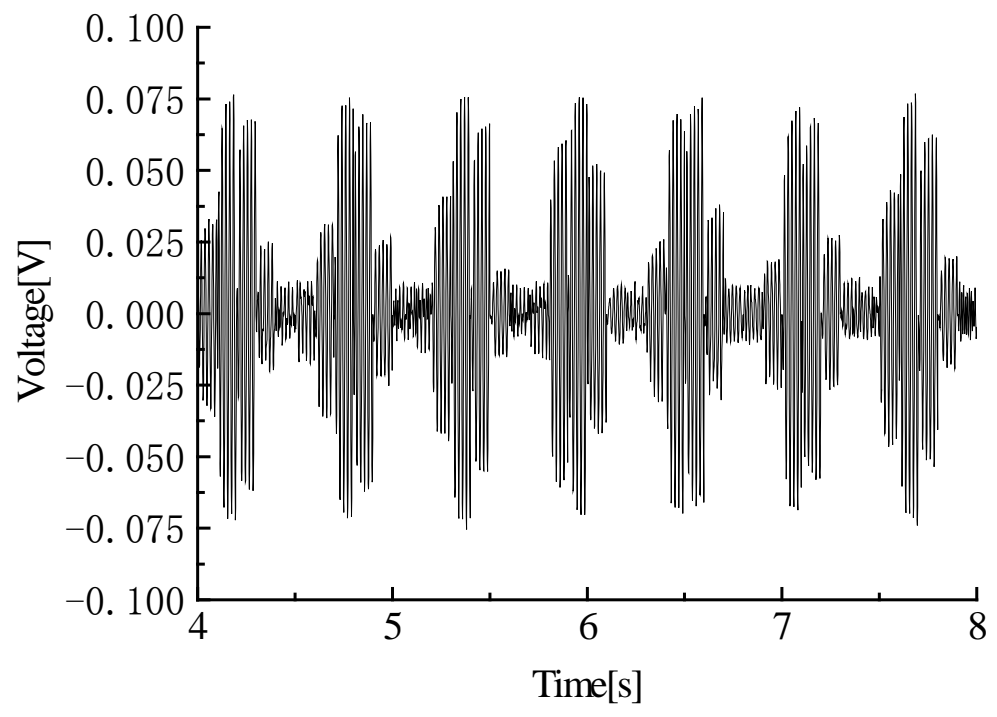

(b)

Figure 18. Self-induced voltage under continuously varying direct current input for the excitation coil: (a) the original waveform under the direct current input from 0A to 1A continuously, (b) the enlarged waveform during the movement of the damper rod shown in the circle of (a).

\subsection{Damping performance and MR effect}

Figure 19 shows the damping forces of the damper various magnetic fields with the coil currents ranging from $0 \mathrm{~A}$ to $0.75 \mathrm{~A}$. Similar to conventional MR dampers, this D-DSMRD shows an obvious MR effect with the peak damping force varying from $60 \mathrm{~N}$ at $\mathrm{I}=0 \mathrm{~A}$ to about $170 \mathrm{~N}$ at $\mathrm{I}=0.75 \mathrm{~A}$. The effective damping coefficient of the D-DSMRD versus coil currents at the damper displacement $l_{\mathrm{p}}=5 \mathrm{~mm}$ is shown in Figure 20. Obviously, it shows an increasing trend with the magnetic field additions. When the current is $0 \mathrm{~A}$, the effective damping coefficient is under $70 \mathrm{kN} \cdot \mathrm{s} / \mathrm{m}$, however, the coefficient could reached more than $150 \mathrm{kN} \cdot \mathrm{s} / \mathrm{m}$ when the coils current is $0.75 \mathrm{~A}$.

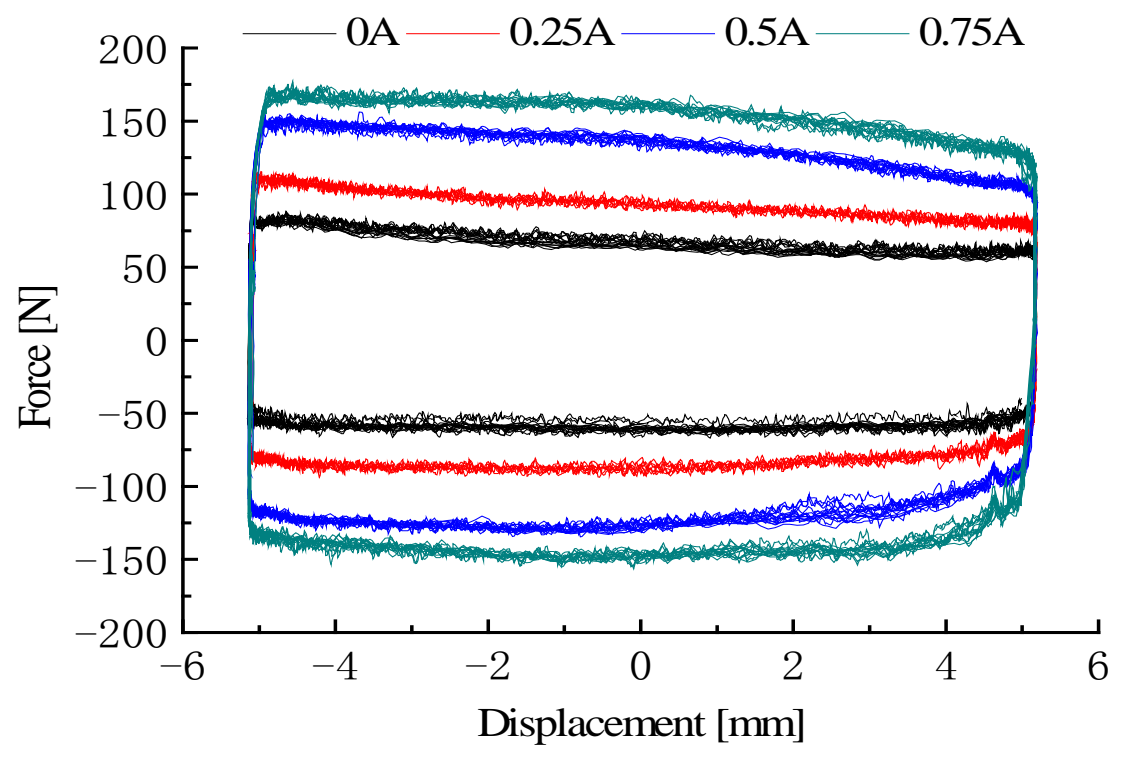

Figure 19. Diagram of experiment force-displacement 


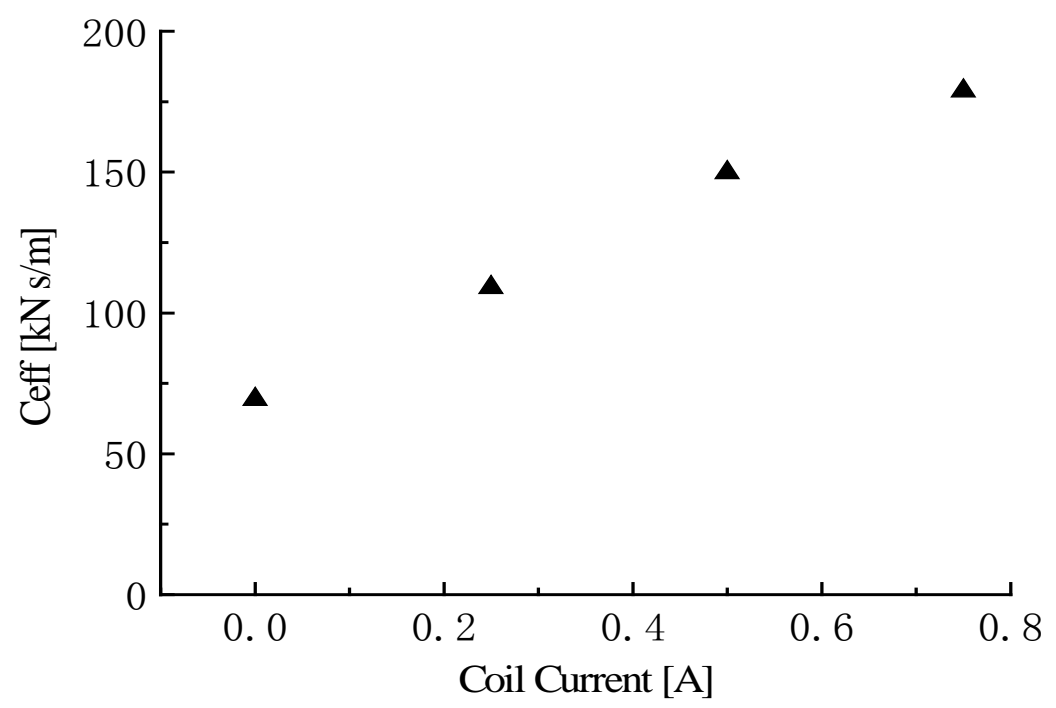

Figure 20. Equivalent coefficient of D-DSMRD versus coil currents, $f=0.2 \mathrm{~Hz}$.

\section{Conclusion}

In this paper, a differential displacement self-induced magnetrheological damper (D-DSMRD) based on the integrated linear variable differential sensor (ILVDS) technology was developed. The major structure of the D-DSMRD is the excitation coil wounded on the piston and two self-induced coils wounded on the winding cylinder. In the D-DSMRD, excitation coil was multiplexed by input direct current which magnetizes MRF in the gap and $1 \mathrm{kHz}$ frequency carrier of alternating current for the ILVDS.

The performance of the embedded sensor was evaluated through four selected experiments: (a) induced-voltage at different positions; (b) induced voltage under different DC inputs for the excitation coil; (c) induced voltage under different displacements; and (d) induced voltage under continuously varying Dc inputs. The results indicated that the induced voltage is proportional to the displacement but varies little with the DC inputs from the exciting coil. Additionally, the developed D-DSMRD has a similar performance as conventional MR damper. The damping coefficient of the damper increases steadily with the coil current input.

This research is expected to not only provide a new method to decrease the installation spaces and maintain spending of MR damper system, but also lead to potential applications of MR damper in industries, such as vehicles, bridges, and so on. Because of the proposed D-DSMRD structure, displacement sensors outside the MR damper are likely not to be needed.

\section{Acknowledgements}

This research was financially supported by the University of Wollongong UIC grant, the National Natural Science Foundation of China (No. 51165005), the Educational Commission and International Cooperation Project of Jiangxi Province of China (No. GJJ13341, 20132BDH80001), and the Visiting Scholar Foundation of Key Laboratory of Fluid Power and Mechatronic Systems at the Zhejiang University (No. GZKF-201207). 


\section{References}

Bossis G, Lacis S, Meunier A and Volkov O. (2002) Magnetorheological fluids. Journal of Magnetism and Magnetic Materials 252: 224-228.

Chen C and Liao WH (2012) A self-sensing magnetorheological damper with power generation. Smart Materials and Structures 21(2): 1-14.

Choi YT and Wereley NM (2009) Self-powered magnetorheological dampers. Journal of Vibration and Acoustics 131(4): 707-714.

Gordaninejad F, Saiidi M, Hansen BC, Ericksen EO and Chang FK (2002) Magneto-Rheological Fluid Dampers for Control of Bridges. Journal of Intelligent Material Systems and Structures 13(2-3): 167-180.

Jolly MR, Bender JW and Carlson JD (1999) Properties and applications of commercial magnetorheological fluids. Journal of Intelligent Material Systems and Structures 10(1): 5-13.

Lam KH, Chen ZH, Ni YQ and Chan HLW (2010) A magnetorheological damper capable of force and displacement sensing. Sensors and Actuators A: Physical 158: 51-59.

Lee HS and Choi SB (2000) Control and response characteristics of a magneto-rheological fluid damper for passenger vehicles. Journal of Intelligent Material Systems and Structures 1(11): 80-87.

Li WH, Liu B, Kosasih PB and Zhang XZ (2007) A 2-DOF MR Joystick for Virtual Reality Applications. Sensors and Actuators A: Physical 15: 1960-1966.

Nehl TW, Betts JA and Mihalko LS (1996) An integrated relative velocity sensor for real-time damping applications. IEEE Transactions on Industry Application 32(4): 873-881.

Peng GR, Li WH, Hu GL and Alici G (2011) Design and simulation of a self-Sensing MR damper. The $15^{\text {th }}$ International Conference on Mechatronics Technology, 30 November to 2 December, 2011, pp: 112-117.

Rabinow J (1948) The magnetic fluid clutch. AIEE Transactions 67: 1308-1315.

Sapinski B (2011) Experimental study of a self-powered and sensing MR-damper-based vibration control system. Smart Materials and Structures 20(10): 1-13.

Wang DH and Bai XX (2011) Pareto optimization-based tradeoff between the damping force and the sensed relative displacement of a self-sensing magnetorheological damper. Journal of Intelligent Material Systems and Structures 22(13): 1451-1467.

Wang DH, Bai XX and Liao WH (2010) An integrated relative displacement self-sensing magnetorheological damper prototyping and testing. Smart Materials and Structures 19(10): 1-19.

Wang DH and Wang T (2009) Principle, design and modeling of an integrated relative displacement self-sensing magnetorheological damper based on electromagnetic induction. Smart Materials and Structures 18(9): 1-20.

Li WH, Wang XY, Zhang XZ and Zhou Y (2009) Development and analysis of a variable stiffness damper using an MR bladder. Smart Materials and Structures 18: 074007.

Wang ZH, Chen ZQ and Spencer BF (2009) Self-powered and sensing control system based on MR damper presentation and application. Proc. of Sensors and Smart Structures Technologies for Civil, Mechanical, and Aerospace Systems, San Diego, 7292: 1-10. 
Yao GZ, Yap FF, Chen G, Li WH and Yeo SH (2002) MR damper and its application for semi-active control of vehicle suspension system. Mechatronics 12: 963-973.

Yoo JH and Wereley NM (2004) Performance of a magnetorheologica hydraulic power actuation system. Journal of Intelligent Material Systems and Structures 15(11): 847-858.

Yu M, Dong XM, Choi SB and Liao CR (2009) Human simulated intelligent control of vehicle suspension system with MR dampers. Journal of Sound and Vibration 319(3-5): 753-767.

Zhu XC, Jing XJ and Cheng L (2012) Magnetorheological fluid dampers: A review on structure design and analysis. Journal of Intelligent Material Systems and Structures 23(8): 839-873. 